ECONOMICS

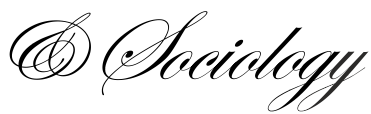

\author{
Beáta Gavurová, \\ Technical University of Košice, \\ Košice, Slovak Republic \\ E-mail:beata.gavurova@tuke.sk \\ Eva Huculová, \\ Technical University of Košice, \\ Košice, Slovak Republic \\ E-mail:eva.huculova@tuke.sk \\ Viliam Kováč, \\ Technical University of Košice, \\ Košice, Slovak Republic \\ E-mail:viliam.kovac@tuke.sk
}

Received: September, 2018 1st Revision: December, 2018 Accepted: May, 2019

DOI: $10.14254 / 2071-$ 789X.2019/12-2/17

JEL Classification: I18
Gavurová, B., Huculová, E., \& Kováč, V. (2019). Quantification of relationship between cardiovascular diseases mortality rate and selected socio-economic indicators - comparative analysis of the Czech Republic and the Slovak Republic.

Economics and Sociology, 12(2), 284-300. doi:10.14254/2071-789X.2019/12-2/17

\section{QUANTIFICATION OF RELATIONSHIP BETWEEN CARDIOVASCULAR DISEASES MORTALITY RATE AND SELECTED SOCIO-ECONOMIC INDICATORS - COMPARATIVE ANALYSIS OF THE CZECH REPUBLIC AND THE SLOVAK REPUBLIC}

ABSTRACT. The paper deals with an issue of the cardiovascular diseases mortality, which is currently the main cause of all the deaths, not only in the Czech Republic and in the Slovak Republic, but also globally. The main objective of the study is to analyse and to quantify the relationship between the cardiovascular diseases mortality rate and the selected socio-economic indicators at the national level of the explored countries. Consequently, the results of the surveyed countries are compared by application a distance method from a fictitious object. As the results of the analysis show, from the selected socio-economic factors, the health expenditures play a significant role - this determinant in the Czech Republic had a higher impact on the possible decrease in mortality than in the Slovak Republic. The other major socio-economic factors are the unemployment rate, the secondary education unemployment rate, the tertiary education unemployment rate, and gross domestic product growth rate. They have different impact on the cardiovascular diseases mortality in the individual countries. This mortality rate is also analysed among the regions where significant regional disparities occur. The results of the comparative study provide an important platform for national and regional policymakers in the health and social field. They can also provide important information for national and international benchmarking.

Keywords: cardiovascular disease, mortality rate, socio-economic factor, economic indicator, regional disparity, prevention programme, health policy, regression analysis, Czech Republic, Slovak Republic.

\title{
Introduction
}


The process of demographic aging has affected all the countries. It is estimated that the healthcare costs will increase in many countries in the next decades. As some studies state, demographic factors have only partial influence on the healthcare costs development (Medeiros \& Schwierz, 2013). Technological and institutional improvements also represent the main factors of healthcare costs. The current financing of health system in the Slovak Republic and in the Czech Republic is very sensitive of the impacts on demographic aging processes. In the both countries, a strong dependency on public financing of healthcare sector represents a critical point of maintaining health system. The fundamental health determinants and health behaviour of population play a very important role in this entire process too.

In the Slovak Republic, avoidable mortality remains well above an average level of the European Union in spite of its improvements. Mortality after hospitalisation due to heart attack or stroke has decreased for the last decades and it signalises an improvement of acute healthcare. The Czech Republic has much better health results than many economies of the central and eastern Europe, especially in the parameters such as a rate of surviving after hospitalisation due to ischaemic stroke is or avoidable mortality. However, it lags behind the Organisation for Economic Co-operation and Development member countries average. There are significant differences in the health results among the regions of the both countries. The Czech Republic health system costs are higher as compared with the Slovak Republic costs at a level of 1,797 EUR per inhabitant. On the other hand, the Slovak Republic spends less financial resources on the health system than a majority of the European Union countries in the absolute expression, as well as in a gross domestic product ratio. In 2015, it spent 1,538 EUR per inhabitant, whilst the European Union average lies at a level of 2,797 EUR per inhabitant. It represents a share of $6.9 \%$ of gross domestic product in comparison to a share of $9.9 \%$ within the entire European Union. The healthcare costs have kept stable position since the 2008 economic crisis in the Czech Republic, while a rate of the public costs of the total costs at a level of $82.4 \%$ belongs to the highest ones among the Organisation for Economic Co-operation and Development member countries and the Slovak Republic holds very similar position with a level of $80 \%$.

Many behavioural risk factors are frequent in the population groups with a low level of education or income in the Slovak Republic. The occurrence of regular smoking is almost of two thirds higher in the population group with the lowest level of education in comparison with the group with the highest education. The total alcohol consumption in the Slovak Republic is close to the European Union average with a level of 10.21 per adult person in 2015. Also, alcohol consumption remains on a high level in the Czech Republic, while it influences both, premature morbidity and mortality. It has kept a slightly increasing tendency in the last three decades, while in 2015, this trend stands at a level of 11.51 per adult person in the Czech Republic. There is to note that an Organisation for Economic Co-operation and Development member countries average level is 91 per adult person (Organisation for Economic Co-operation and Development, 2017). Risky behaviour and regular smoking occur in the similar population groups in the Czech Republic as well as in the Slovak Republic. Both the risk behaviour and an influence of the risk environment, where alcohol consumption, smoking and obesity belong, are very close to Organisation for Economic Co-operation and Development member countries average, or it exceeds this level. In the Czech Republic, life expectancy could be prolonged of almost 3.5 years by limitation of risk behaviour on a healthy level according to the European Commission (2015). There are also evident links of risky health behaviour to the population with a low level of education or income. People with the lowest level of education list diabetes and daily smoking three times more.

The given aspects justify a significance of solving the issue of the examined relations between the cardiovascular diseases mortality and the socio-economic indicators that influence development of mortality trends on the selected diseases as well as of research of 
the regional disparities. The research subject is also related to a comparison of the observed aspects at the complementary level in the both countries - the Czech Republic and the Slovak Republic, which formed one common country until the year 1993. Consequently, the development of the health parameters and the examined influences several years after the split may provide valuable insights for a health policy formation.

\section{Literature review}

Many foreign research teams examined an influence of the socio-economic and demographic factors on the cardiovascular diseases. Barr (2016) explores the regional disparities in prevalence of mortality with relation to the cardiovascular diseases in his study. The results of that analysis declare the significant racial differences in prevalence of mortality caused by the examined diseases. Similarly, there are found out some disparities in the individual regions. The most significant risk factors are determined as follows - smoking, a high level of cholesterol, a high level of blood pressure, diabetes mellitus, obesity, and insufficient physical activity. The decrease of mortality by $44 \%$ during the period from the year 1980 to the year 2000 is influenced by changes in these risk factors. In conclusion of the study, the author states that examination of the associations between the cardiovascular diseases models and the behavioural factors are inevitable for medical practice. The health determinants represent biosocial phenomena, while a disease and a health state are represented by means of an interaction between biology and social environment.

The geographical patterns in the United States of America are examined by Casper et al. (2016). The authors describe a significant move of districts' concentration with a high level of the cardiovascular diseases mortality from the northeast to the south of the country. The study appeals to an inevitability of the time parameters' research in interpreting geographical changes in the regions' mortality in a particular country. The authors also show that there has been a radical change in a structure of the cardiovascular diseases mortality during previous 40 years. Thus, it is important to examine small extent areas and reveal hidden factors that influence mortality at the national level. These facts are very important in order to understand historical development of mortality in the regions and also causes of a creation of the geographical differences.

Fairfield et al. (2018) focus on a significance of prevention programs for the cardiovascular diseases. In this study, the authors state that the health of the population of the United States of America has not changed for the last decade as well as in the other developed countries, which causes a pressure to increase investments in the health sector. The aim of this study is to examine an influence of risk factors, risk behaviour in relation to the cardiovascular diseases as well as use of health services for cardiovascular diseases treatment. The main task of policies in health area should be setting of prevention programmes which focus on affected risk factors as well as effective use of resources for providing a healthcare. Also these authors claim that it is important to use measures in order to improve health at the regional level and usage of the regional health databases. It will enable to set effective interventions and evaluation mechanisms to monitor their efficiency.

Health literacy is also related to the prevention programmes. Lešková et al. (2011) describe in the study its significance for decreasing the cardiovascular diseases mortality. The authors examine a level of awareness of prevention options with relation to arterial hypertension on a sample of the selected respondents. A questionnaire method is applied for this purpose. Also the authors emphasise that a significant role in cardiovascular diseases development is played by a lifestyle change, alcohol consumption and smoking. Healthcare workers may be important in a change of health behaviour as their main role is to notify of risks and also consequences on risk factors' influences. 
Roth et al. (2017) offer a specific study on a given issue. The authors examine the differences in the cardiovascular diseases mortality in the individual regions of the United States of America and also the differences in the various cardiovascular diseases types. The smaller regional differences are found in the following diseases - myocardial infarction, atrial fibrillation, diseases of aorta and peripheral artery diseases, rheumatic heart diseases, and endocarditis. The authors also emphasise that a mortality in smaller regions, such as in districts, may significantly differ from the mortality values representing a national average. The significance of local and national health policy is confirmed in this way in order to improve health of the population in the country.

Thompson \& Daugherty (2017) inspect the differences between the sexes in cardiovascular diseases prevention. In the study, the authors state that these diseases are considered as a disease dominant for the male population in the past, however, at present, there are more women who die of the cardiovascular diseases than men. It is caused by the biological differences between women and men and by changes in a healthcare between the sexes. The study suggests to reinforce cardiovascular diseases prevention by improving screening examinations, early determination of diagnosis and providing sufficient and suitable cardiovascular diseases treatment for women.

Many authors examine not only gender gaps, but also an influence of a socioeconomic status of an increase of a risk level in cardiovascular diseases mortality. For instance, Clark et al. (2009) do a research in a relation between a socio-economic status and an increase of risk level of cardiovascular diseases creation. The study results show that a low socio-economic status is related to a high risk of these diseases. It would be interesting to explore an influence of a socio-economic status in the countries with low and medium incomes, however, such studies are very rare.

Houweling \& Kunst (2009) explore an influence of a socio-economic status of parents and households, where a child was born, on child mortality in lower and middle income countries. At the present time, there are some agreements on financing healthcare, which are related to a higher child healthcare, vaccination and treatment of respiratory diseases that are considered as minor in poor countries in less educated communities. The authors appeal to a high level of necessity for setting an adequate policy in order to eliminate inequalities in health area and to provide a suitable intervention programmes for socially and economically disadvantaged groups.

Also Griskevicius et al. (2011) research an influence of the economic indicators on the regional differences in mortality. The study results show that mortality level depends on a particular economic indicator - income. Consequently, the significant differences in mortality between low-income and high-income countries are proved.

According to Glymour et al. (2014), an elimination of the differences in a socioeconomic status may be a significant determinant in decreasing the cardiovascular diseases mortality. The authors emphasize a significance of a socio-economic status on this mortality development, as the negative points of socio-economic disadvantage have a great impact on a human during the entire life. Any other disadvantage radically increases a risk of cardiovascular diseases creation in the subsequent periods.

Svihrova et al. (2016) evaluate an importance of solving high level of the cardiovascular diseases mortality issue from an international point of view. The main aim of the World Health Organization prevention programmes is to eliminate this mortality for people younger than 65 years. The authors analyse in their study the development of mortality in the various groups of cardiovascular diseases in the Slovak Republic. In some diagnoses, there is found out a decrease in mortality in all the age categories that is different in the individual regions. The authors appeal to a necessity of a constant solving of a cardiovascular 
diseases issue as the level of their mortality is the highest one within the European Union for a long period of time.

Also Kabayama \& Kamide (2018) deal with and an influence of the socio-economic factors on cardiovascular diseases development in their study. The authors notify of a necessity to implement different mechanisms in order to eliminate the cardiovascular diseases, however, their positive impacts may be evident in a later period of time.

Many authors also examine influence of other factors on mortality development. The authors, such as Elo (2009), Masters et al. (2014), Dereuddre et al. (2016), Walsemann et al. (2016) focus on gender differentiation in mortality in relation to the non-communicable disease. Higher risk level of cardiovascular diseases creation is determined in men who are socially and economically more disadvantaged. However, they suggest that a range of socioeconomic inequalities change during time and it is different for each country (Elo et al., 2009, Glymour et al., 2014; Walsemann et al., 2016).

Many research groups of sociologists, demographers, economists and social epidemiologists express their opinions to the topics of health economics and health policy (Elo, 2009; Zahra, 2015). These authors describe social inequalities in health as very important and a difficult issue. The several authors also examine links among the cardiovascular diseases, the socio-economic inequalities and the treatment costs within health economics (Suhrcke et al., 2006; Glymour et al., 2014). Their treatment as well as operational processes, which are related to it, have had increased in the last decades (Bhatnagar et al. 2016). However, at the present time, the non-communicable diseases and within this group, especially the cardiovascular diseases and diabetes mellitus represent the main threat for human health and life expectancy (Suhrcke et al., 2006; Zahra et al., 2015).

The given results of the selected research studies declare a long-term attention of the analytical research teams as well as specialists in the socio-economic factors and the other factors that influence the cardiovascular diseases mortality and also search for possibilities to eliminate it. In spite of the fact that the given research studies are basically heterogeneous, their results are in the same process and implication line and they have significant regional, national and global significance. Consequently, there is evident pressure on formation of efficient regional and national policies in health area in order to decrease mortality in the individual groups of the diagnoses. These are inevitable for maintaining health and social system of the countries in the processes of global demographic population aging.

\section{Methodological approach}

The main objective of the study is to analyse and to quantify a relationship between the cardiovascular mortality rate and the selected socio-economic indicators at the national level of the Slovak Republic and the Czech Republic. The selection of the countries is done on the basis of their common and long-term historical development as well as comparable economic expansion and geographical breakdown.

Linear regression is employed to quantify the relation between the mortality rate and the selected socio-economic indicators. Consequently, there is performed a comparison of the selected countries at regional level and the mortality rate caused by the cardiovascular diseases in the individual regions is compared by means of a distance method from a fictitious object (Stankovičová \& Vojtková, 2007). The analysis included the 14 regions of the Czech Republic and the 8 self-governing regions of the Slovak Republic. It is referred as the third level of the Nomenclature of Territorial Units for Statistics. The examined regions are compared with regions that reach the lowest level of cardiovascular mortality.

The dependant variable is composed of the cardiovascular mortality rate share on the total mortality rate marked $M S$. The database includes the data obtained from the databases, 
where Organisation for Economic Co-operation and Development Health Statistics 2018, the World DataBank, the Datacube - the Statistical Office of the Slovak Republic, the National Health Information Center of the Slovak Republic database, the Institute of Health Information and Statistics of the Czech Republic database and Public Database of the Czech Statistical Office belong. The researched data covers a period from the year 2001 to the year 2016.

The following macroeconomic indicators are selected for the both linear regression models as the independent variables. Firstly, the unemployment variable marked $U$ represents total unemployment rate as a share of the unemployed population of the labour force as percentage. It is applied also in the several studies in such analyses (Gravelle et al., 2012; Halliday, 2014; European Commission, 2016; Gavurová et al., 2017a,b). Secondly, the variables of the unemployed population with secondary education marked $S E U$ and the unemployed population with tertiary education marked TEU from 25 years of age to 64 years of age is involved in the model. Such respondents are analysed by the other foreign studies of Houweling \& Kunst (2009), Black et al. (2015), and James (2015). In this context, there are examined the effects of the gross domestic product growth rate as year-to-year percentage at market prices based on constant local currency (Granados, 2012; Renton et al., 2012; Reeves et al., 2013). Successively, the health expenditures variable demonstrates the total health expenditures as percentage of gross domestic product marked $H E$, which measures the final consumption of healthcare goods and services applied in the studies of van Baal \& Wong (2012), de Meijer et al. (2013), Schofield et al. (2013), Vandersteegen et al. (2015), Jakubowska (2016) and Halaskova, 2018. The last but not least variable, which is involved, is the alcohol consumption indicator defined as annual sales of pure alcohol in litres per person aged from 15 years and older marked $A C$, whereas alcohol consumption is associated with numerous harmful health and social consequences (Riemenschneider et al., 2016).

The fundamental regression model equation looks like as follows:

$$
M S=\beta_{0}+\beta_{U} U+\beta_{S E U} S E U+\beta_{T E U} T E U+\beta_{H E} H E+\beta_{A C} A C
$$

The $\beta$ coefficient represent the estimated coefficients of the given independent variables and the $\beta_{0}$ coefficient a constant value.

The abbreviations of the regions visualised in the figures are following. The Slovak Republic regions are marked as follows: the Banská Bystrica Self-Governing Region - BC, the Bratislava Self-Governing Region - BL, the Košice Self-Governing Region - KI, the Nitra Self-Governing Region - NI, the Prešov Self-Governing Region - PV, the Trenčín SelfGoverning Region - TC, the Trnava Self-Governing Region - TA, and the Žilina SelfGoverning Region - ZI. The Czech Republic regions are mentioned in this way: the Capital City Prague - PHA, the Central Bohemian Region - STČ, the Hradec Králové Region $\mathrm{KHH}$, the Karlovy Vary Region - KVK, the Liberec Region - LBK, the Moravian-Silesian Region - MSK, the Olomouc Region - OLK, the Pardubice Region - PAK, the Plzen Region - PLK, the South Bohemian Region - JHČ, the South Moravian Region - JHM, the Ústí Region - ÚLK, the Vysočina Region - VYS, and the Zlín Region - ZLK.

\section{Conducted research and results}

The relation between cardiovascular mortality and the selected socio-economic indicators at the national level of the Czech Republic and the Slovak Republic is tested on the basis of the linear regression. The indicators, which are considered, are increase of the gross domestic product of a given country, total expenditures on healthcare as percentage of gross domestic product, total unemployment rate, secondary education unemployment rate, tertiary 
education unemployment rate, and alcohol consumption. Secondly, the research focuses on evaluation of cardiovascular mortality occurrence at the regional level of the explored countries, while using the method of a distance from a fictitious object. The actual status and severity of these diseases in the individual regions are compared in these countries.

The dependent variable expressing a share of the cardiovascular mortality rate of the total mortality is estimated using the linear regression model. There is examined what influence may be done by the defined variables on mortality that is related to this disease. The results are compared between the individual countries. The regression models for the both countries are found statistically significant by the testing procedures when recognising them as a whole. However, some of their variables do not fulfil the requirements of the statistical significance. Consequently, the partial models are created as they are absent in the terms of these statistically insignificant variables. These multilevel models are tested on the possible and specific issues of heteroscedasticity, autocorrelation and multicollinearity. However, none of them is found out in the tested models. Residuals come from the normal probability distribution and it is confirmed by the carried out tests.

\subsection{The national level}

Subsequently, the corrected linear regression models that focus on the cardiovascular mortality contain only the statistically significant variables, including unemployment rate, the tertiary education unemployment rate, the health expenditures and the gross domestic product growth rate. The results from the corrected model are explained in Table 1 and Table 2. Table 1 provides the data of the Slovak Republic model that explains $84.58 \%$ of variability of the dependent variable. The model is statistically significant as a whole, as well as all the involved variables, which the unemployment rate, the tertiary education unemployment rate and the health expenditures belong among. Similarly, Table 2 embodies the outcome of the second tested model for the Czech Republic. It explains $89.07 \%$ of variability of the dependent variable. The Czech Republic model is also statistically significant as a whole, as well as all of its variables. These are the unemployment rate, the health expenditures and the gross domestic product growth rate.

It may be stated that if the unemployment rate variable increases by one percentage point, the mortality rate of cardiovascular diseases will increase of $0.65 \%$ in the Slovak Republic and at a level of $0.96 \%$ in the Czech Republic. The tertiary education unemployment rate variable has even higher influence. It means that if unemployment of the Slovak tertiary educated students is increased by one percentage point, the cardiovascular mortality rate will increase by $1.78 \%$ in average. The study by Halliday (2014) shows the similar conclusions and it also emphasises that an increase of the unemployment rate by one percentage point increases a probability of the cardiovascular diseases death risk of more than $7 \%$. Lower mortality rate of patients when considering non-communicable diseases is expected in the countries with high income per inhabitant and a higher employment rate.

Table 1. The Slovak Republic regression model

\begin{tabular}{lrrrr}
\hline variable & estimated coefficient & standard error & t-test statistic & \multicolumn{1}{c}{-value } \\
\hline constant & 0.406013 & 0.039320 & 10.326 & $2.53 .10^{-7}$ \\
\hline $\mathrm{U}$ & 0.006522 & 0.001083 & 6.022 & $6.01 .10^{-5}$ \\
\hline TEU & 0.017798 & 0.002341 & -7.604 & $6.30 .10^{-6}$ \\
\hline HE & -0.016035 & 0.004390 & 3.653 & $3.31 .10^{-3}$ \\
\hline
\end{tabular}

Source: own elaboration by the authors 
On the other hand, the study by Gravelle et al. (2012) does not observe any statistically significant relation among income disparities, employment and population health. There is observed no statistically significant influence on tertiary education unemployment rate in the Czech Republic too.

The health expenditures are considered as a key factor. Their influence on the cardiovascular mortality is higher in the Czech Republic than in the Slovak Republic. Table 1 and Table 2 identify this variable as statistically significant in the both models. If the health expenditures variable increases by one percentage point in average, the mortality rate of cardiovascular diseases of the Slovak Republic population will decrease by $1.6 \%$ in average, while in a case of the Czech Republic population it may decrease by $4.16 \%$ in average. In the Czech Republic model, a positive relation between the gross domestic product growth rate variable and this mortality rate is established. If it increases by one percentage point in average, the cardiovascular mortality rate will decrease by $0.37 \%$ in average in the Czech Republic.

Table 2. The Czech Republic regression model

\begin{tabular}{lrrrr}
\hline \multicolumn{1}{c}{ variable } & estimated coefficient & standard error & t-test statistic & p-value \\
\hline constant & 0.722303 & 0.038994 & 18.523 & $1.21 .10^{-9}$ \\
\hline U & 0.009608 & 0.001616 & 5.947 & $9.64 .10^{-5}$ \\
\hline TEU & -0.003677 & 0.000862 & -4.265 & $1.33 .10^{-3}$ \\
\hline HE & -0.041615 & 0.005009 & -8.308 & $4.55 .10^{-6}$ \\
\hline
\end{tabular}

Source: own elaboration by the authors

Such changes are required in a context of a positive influence on higher health expenditures that are caused by lower mortality in patients of the circulatory system diseases in the both compared countries. This macroeconomic indicator represents one of a few alternatives of how government interventions may contribute to lowering mortality rate in the Czech Republic and in the Slovak Republic besides increased awareness, support of cardiovascular diseases prevention programmes and healthier lifestyle. On the other hand, fast growth of the health expenditures represents a burden for financing the public systems. According to the Organisation for Economic Co-operation and Development recommendations, in a case the countries will not accept necessary reforms in a short time period, economy of the developed countries will be unbearable and unsustainable until the year 2050 (Organisation for Economic Co-operation and Development, 2015). Other statistics of this organisation considering purchasing power parity state that the costs per patient have increased, for instance by $7 \%$ in Austria, and by $11 \%$ in the United States of America as opposed to the year 2012 (European Commission, 2016). The growth of expenditures on the public health system is caused by an implementation of new treatment procedures and new medical technologies, higher patients' demands, increasing medical needs of aging population as well as worse population lifestyle (Organisation for Economic Co-operation and Development, 2015).

\subsection{The regional level}

Figure 1 illustrates the development rate of the population mortality in the observed countries that is caused by the cardiovascular mortality from the year 2001 to the year 2016 . In the Slovak Republic, the cardiovascular mortality was the main reason of the total population mortality during the monitored period. Even in the Czech Republic, the highest 
rate of this mortality at a level of $52.8 \%$ is comparable to the one in the Slovak Republic Slovakia at the beginning of the explored period.

In the following years, the decreasing trend of mortality due to the cardiovascular diseases is observed in the both countries with even a higher tendency. In spite of this fact, the number of deaths slightly increased in 2016 and in the Slovak Republic. It represented the largest mortality rate at a level of $48.21 \%$ out of all the other groups of the diseases in the country. This negative trend is ongoing in the Czech Republic too, where mortality is caused by the cardiovascular diseases by a share of $44.19 \%$ out of all the groups of the diseases. Similarly, the other foreign studies recorded a high trend of this mortality within a group of the non-communicable diseases (Dukát \& Baráková, 2006; Bhatnagar et al., 2016; Korda et al., 2016; World Health Organization, 2018).

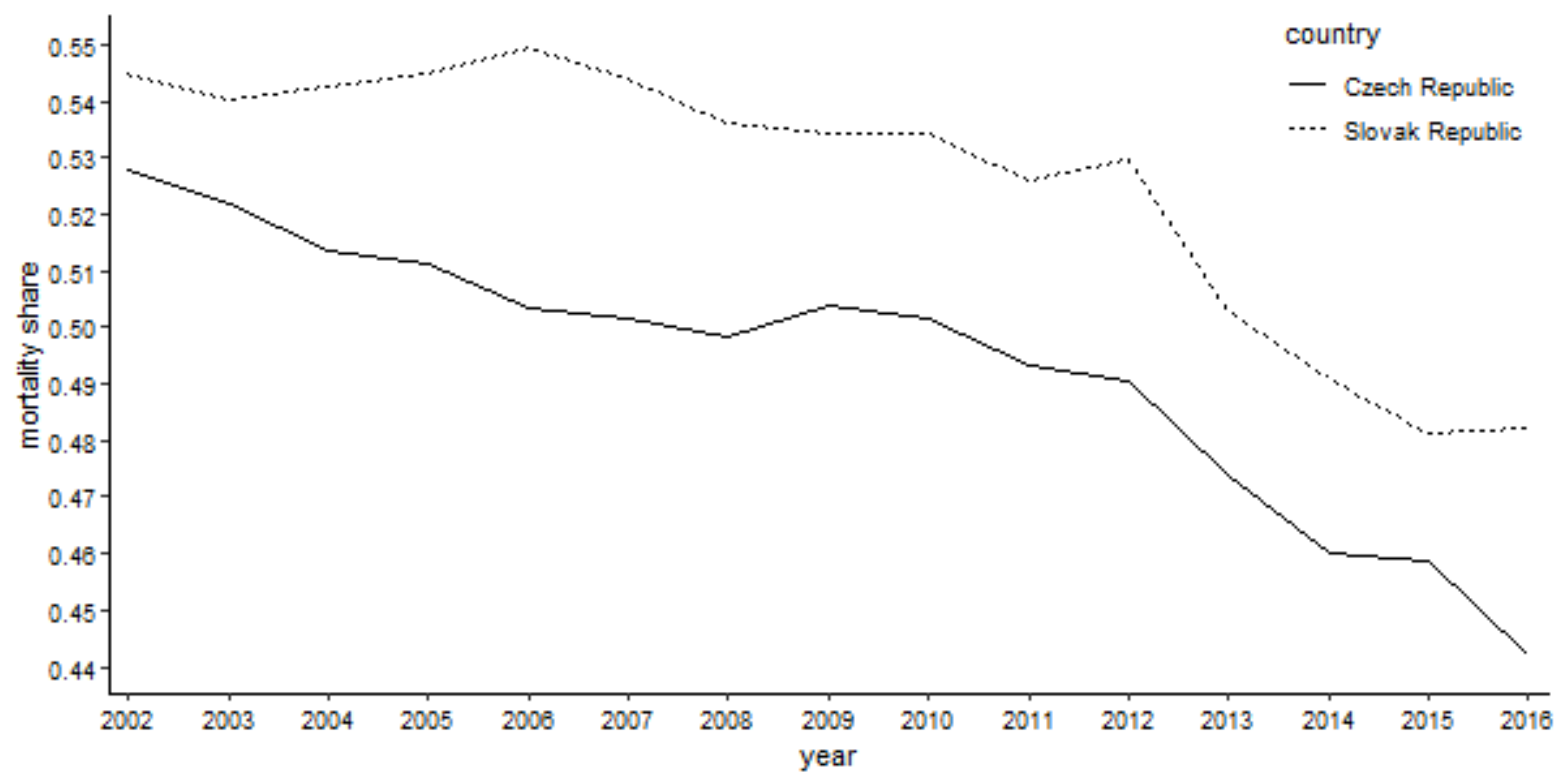

Figure 1. A share of the cardiovascular diseases mortality rate of the total mortality in the

Czech Republic and in the Slovak Republic

Source: own elaboration by the authors

Figure 2 illustrates the mortality rate of the Slovak population. The lowest cardiovascular diseases mortality rate is evident in the eastern part of the country, especially the lowest one is recorded in the Trnava Self-Governing Region in 2016. On the other hand, the highest mortality rate is recorded in the Nitra Self-Governing Region and the Trenčín Self-Governing Region. 


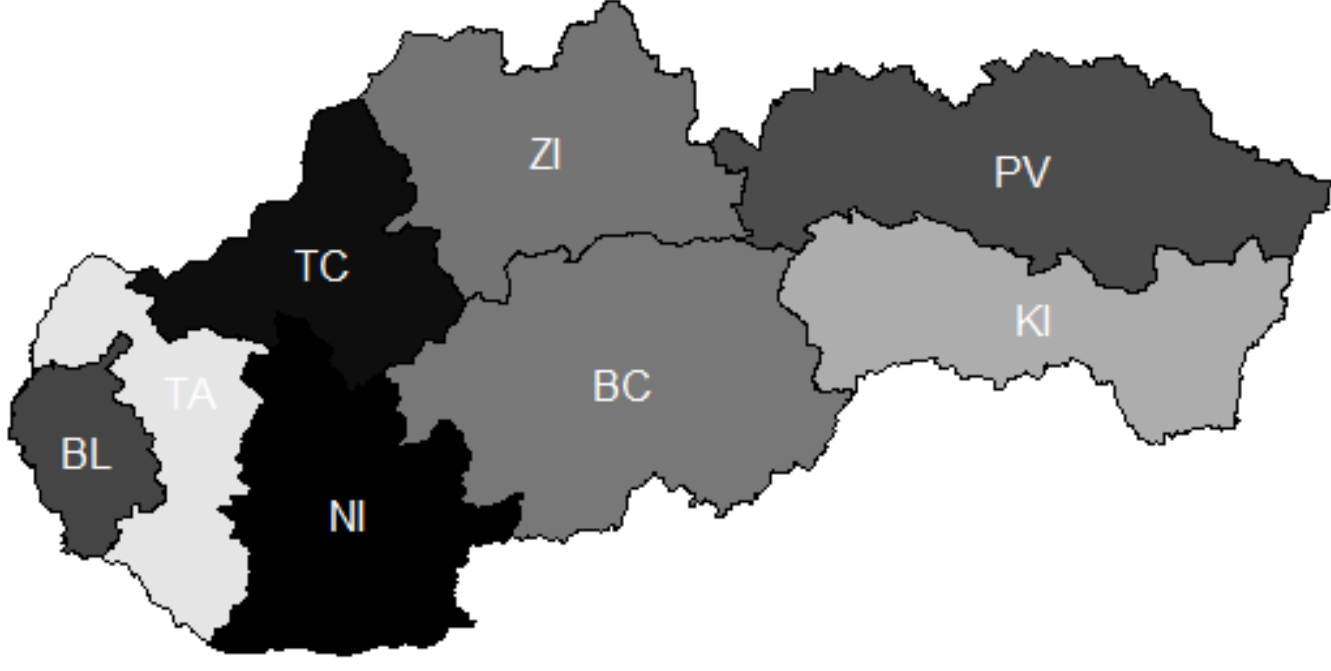

49.5

49.0

48.5

48.0

47.5

47.0

46.5

46.0

Figure 2. The cardiovascular diseases mortality rate in the Slovak Republic self-governing regions

Source: own elaboration by the authors

In the Czech Republic, as Figure 3 demonstrates, the highest cardiovascular mortality rate is showed in the Zlín Region in the year 2016, where the mortality rate of these diseases is at level of $47.27 \%$. The lowest mortality rate is recorded in the South Bohemian Region standing over a level of $39.87 \%$ in the last years.

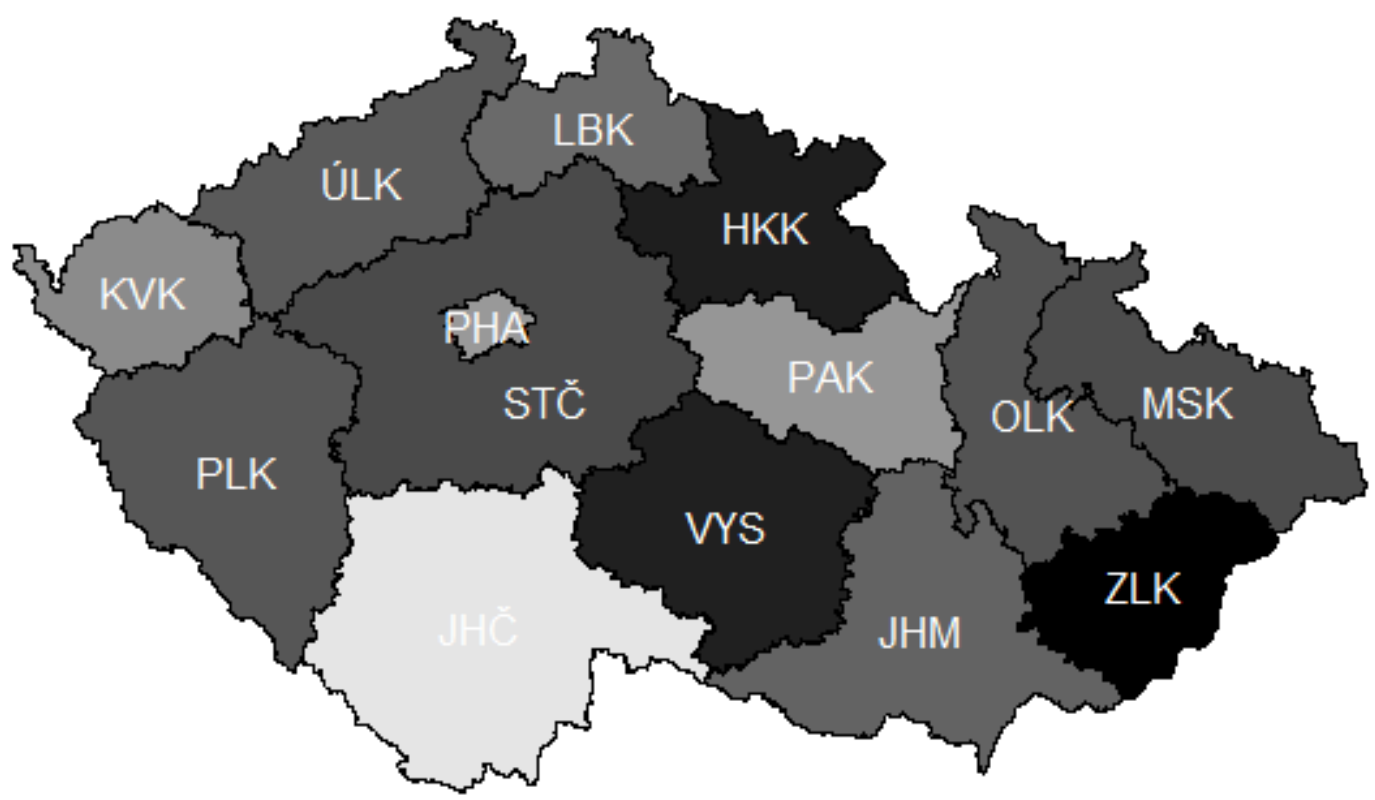

Figure 3. The cardiovascular diseases mortality rate in the Czech Republic regions Source: own elaboration by the authors

A method of distance from a fictitious object is applied to research disparities in the cardiovascular mortality at the regional level by creating an essential indicator, which is established on the data of the 14 regions of the Czech Republic and the 8 self-governing regions of the Slovak Republic in this analysis. As Figure 4 suggests, a fictitious object is most frequently localised in the Bratislava Self-Governing Region that has the lowest cardiovascular diseases mortality rate in a comparison with the other self-governing regions during the monitored period. The highest distance from a fictitious object represented by the 
Bratislava Self-Governing Region is reached by the Banská Bystrica Self-Governing Region, the Prešov Self-Governing Region and the Trenčín Self-Governing at the beginning of the observed period until the year 2006. Since that time, the Prešov Self-Governing Region and the Trenčín Self-Governing Region are distant significantly, for instance of over 8 points in the year 2003. There has been a significant change in a number of deaths in the individual regions for the last three years. In the year 2016, the Trnava Self-Governing Region obtained a status of a fictitious object with the lowest cardiovascular mortality rate. The Nitra SelfGoverning Region and the Trenčín Self-Governing Region are distant of approximately 4 points from a new fictitious point and in the both cases with the cardiovascular diseases mortality almost of a half of the total mortality.

The same method is applied to research the mortality rate in the Czech Republic during the same time period in order to compare the both countries. Figure 5 shows the development of the regional disparities among the regions of the Czech Republic. In this case, the status of a fictitious object is obtained by the different regions, which the Capital City Prague, the Karlovy Vary Region, and the South Bohemian Region alternate among. There has been observed more stable and leading status of a fictitious object with a relatively low cardiovascular diseases mortality rate in the South Bohemian Region since 2012.

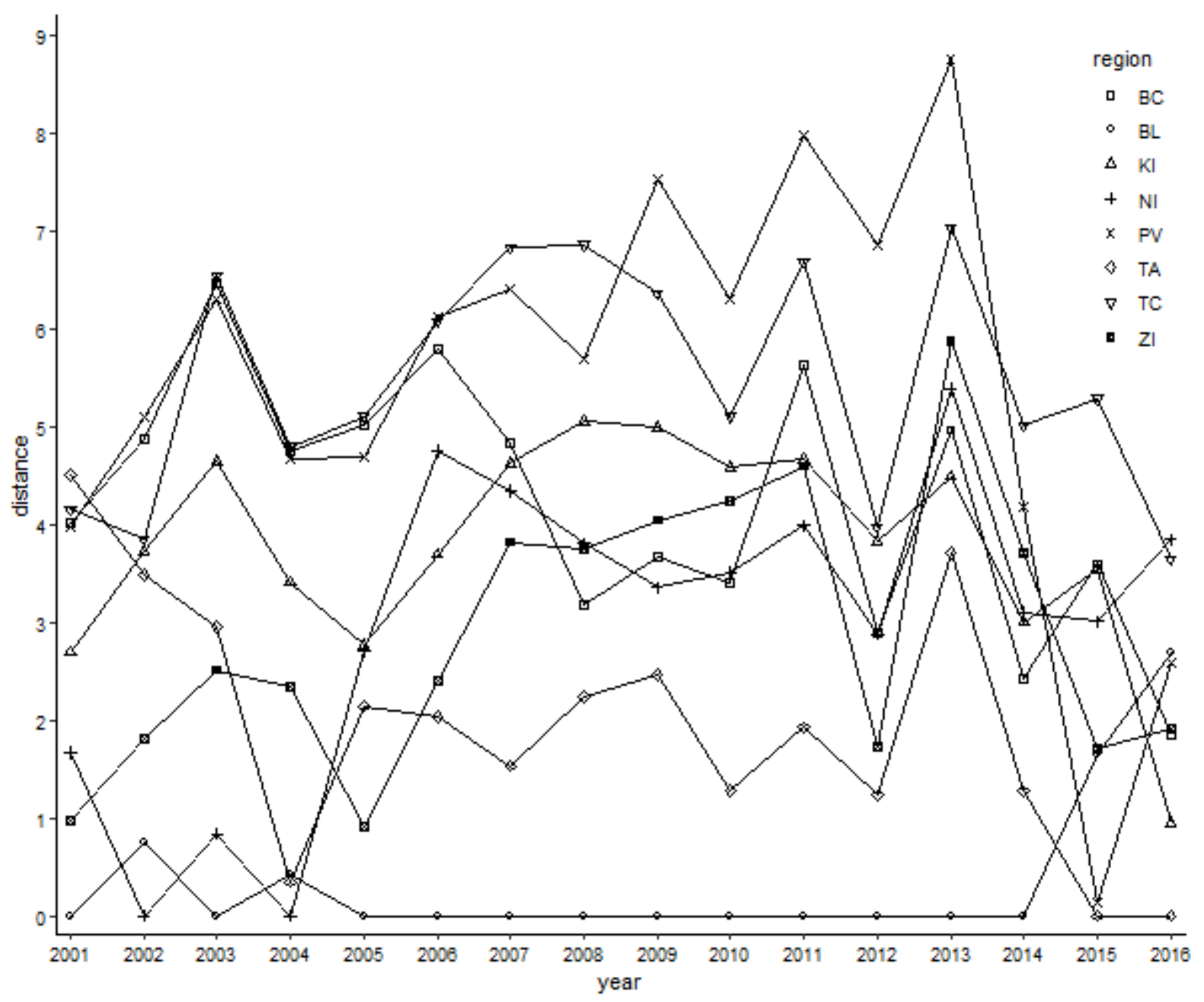

Figure 4. Distance from a fictitious object of the Slovak Republic self-governing regions Source: own elaboration by the authors 


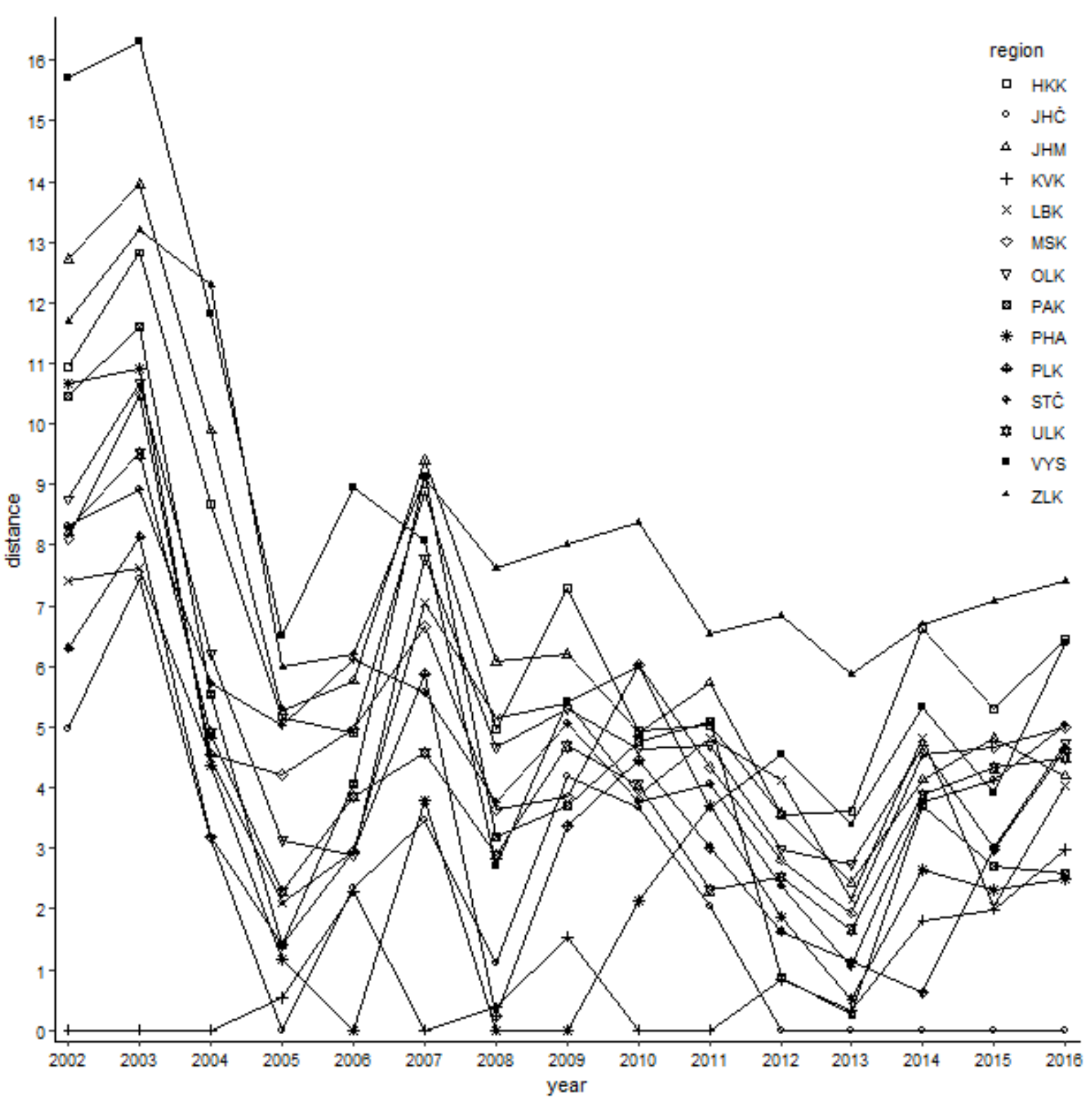

Figure 5. Distance from a fictitious object of the Czech Republic regions Source: own elaboration by the authors

The largest differences are found among the regions where mortality was prevalent in the first years of the monitored period with the highest extremes in the year 2003, when the Vysočina Region was distant from a leading object represented by the Karlovy Vary Region of more than approximately 16 points. This mortality rate disparity among the regions is doubled in a comparison to the Slovak Republic self-governing regions with the largest distance of over 8 points in the year 2013. The differences in the Czech Republic regions have been reduced throughout the explored period. The smallest differences are found just right in the year 2013. Since then, the trend has got worse and the differences among the regions have been increasing. It is an opposite tendency to the Slovak Republic trend - the regional disparities have been constantly decreasing for the last four years, while the lowest disparity is evident in the year 2016. 


\section{Conclusion}

A relation between the cardiovascular mortality of the population and the socioeconomic factors in the both compared countries is determined using the linear regression model. The total health expenditures represent the most significant factor out of all the selected researched socio-economic factors, while they also represent the largest difference among the influences of the mortality rate caused by the cardiovascular diseases between these two countries. The growth of the total health expenditures has a higher influence level on mortality elimination in the Czech Republic than in the Slovak Republic. The other significant socio-economic factors are the unemployment rate, the tertiary education unemployment rate in the Slovak Republic, and the gross domestic product growth rate in the Czech Republic. In the both countries, cardiovascular mortality reach the highest rate of total mortality. This negative development is ongoing. Mortality rate is also analysed in the individual regions, where the significant regional differences are observed. In the Slovak Republic, the highest cardiovascular mortality rate is registered in the Nitra Self-Governing Region, while in the Czech Republic it is in the Zlín Region. The influence of the geographical area and the population density on the cardiovascular mortality is not demonstrated as the both regions do not belong to the largest ones in the given countries in the terms of area and population size. The largest difference in a number of deaths in the Slovak Republic is observed in the year 2013 among the individual regions, while in the Czech Republic, these regional disparities reached their peak in the year 2001, as opposed to the Slovak Republic, they have been constantly increasing. Vice versa, an opposite trend reigns in the Slovak Republic, which a slightly decreasing tendency have occurred in the cardiovascular mortality among the self-governing regions during the explored period in.

\section{Acknowledgement}

This work is supported by the Scientific Grant Agency of the Ministry of Education, Science, Research and Sport of the Slovak Republic and the Slovak Academy Sciences as part of the research project VEGA 1/0846/18 Evaluation of the Efficiency of Public Procurement of Selected Commodities in Healthcare Facilities in the Slovak Republic.

\section{References}

Barr, D. A. (2016). Geography as Disparity. The Shifting Burden of Heart Disease. Circulation, 133, 1151-1154. Retrieved from https://www.ahajournals.org/doi/full/10.1161/CIRCULATIONAHA.116.021764. https://doi.org/10.1161/CIRCULATIONAHA.116.021764.

Bhatnagar, P., Wickramasinghe, K., Wilkins, E., \& Townsend, N. (2016). Trends in the epidemiology of cardiovascular disease in the UK. BMJ Publishing Group, 102(24), 1945-1952. Retrieved from https://heart.bmj.com/content/102/24/1945. https://doi.org/10.1136/heartjnl-2016-309573.

Black, D. A., Hsu, Y., \& Taylor, L. J. (2015). The effect of early-life education on later-life mortality. Journal of Health Economics, 44, 1-9. Retrieved from https://www.sciencedirect.com/science/article/pii/S016762961500082X. https://doi.org/10.1016/j.jhealeco.2015.07.007.

Casper, M., Kramer, M. R., Quick, H., Schieb, L. J., Vaughan, A. S., \& Greer, S. (2016). Changes in geographic patterns of heart disease mortality in the United States: 1973 to 2010. Circulation, 133(12), 1171-1180. Retrieved from: 
https://www.ahajournals.org/doi/full/10.1161/CIRCULATIONAHA.115.018663. https://doi.org/1010.1161/CIRCULATIONAHA.115.018663.

Clark, A. M., DesMeules, M., Luo, W., Duncan, A.S., \& Wielgosz, A. (2009). Socioeconomic status and cardiovascular disease: risks and implications for care. Nature Reviews Cardiology, 6, 712-722. Retrieved from: https://www.nature.com/articles/nrcardio.2009.163. https://doi.org/10.1038/nrcardio.2009.163.

de Meijer, C., O'Donnell, O., Koopmanschap, M., \& van Doorslaer, E. (2013). Health expenditure growth: Looking beyond the average through decomposition of the full distribution. Journal of Health Economics, 32(1), 88-105. Retrieved from: https://www.sciencedirect.com/science/article/pii/S0167629612001701.

https://doi.org/10.1016/j.jhealeco.2012.10.009

Dereuddre, R., Van de Velde, S., \& Bracke, P. (2016). Gender inequality and the 'East-West' divide in contraception: An analysis at the individual, the couple, and the country level. Social Science \& Medicine, 161, 1-12. Retrieved from: https://www.sciencedirect.com/science/article/pii/S0277953616302581. https://doi.org/10.1016/j.socscimed.2016.05.030.

Dukát, A., \& Baráková, A. (2006). Epidemiologické aspekty vzostupného trendu chronického srdcového zlyhávania. Aká je realita v našich podmienkach?. Via Practica, 3(9), 385389. Retrieved from http://www.viapractica.sk/index.php?page=pdf_view\&pdf_id=83\&magazine_id=1 .

European Commission. (2015). Comparative efficiency of health systems, corrected for selected lifestyle factors - Final report. Retrieved from https://ec.europa.eu/health//sites/health/files/systems_performance_assessment/docs/20 15_maceli_report_en.pdf.

European Commission. (2016). Joint Report on Health Care and Long-Term Care Systems and Fiscal Sustainability. European Economy Institutional Papers, 37. Retrieved from https://ec.europa.eu/info/publications/economy-finance/joint-report-health-care-andlong-term-care-systems-fiscal-sustainability-0_en. https://doi.org/10.2765/680422.

Elo, I. T. (2009). Social Class Differentials in Health and Mortality: Patterns and Explanations in Comparative Perspective. Annual Review of Sociology, 35, 553-572. https://doi.org/10.1146/annurev-soc-070308-115929.

Fairfield, K. M., Black, A. W., Lucas, F. L., Siewers, A. E., Cohen, M. C., Healey, C. T., Briggs, A. C., Han, P. K. J., \& Wennberg, J. E. (2018). Behavioral Risk Factors and Regional Variation in Cardiovascular Health Care and Death. American Journal of Preventive Medicine, 54(3), 376-384. Retrieved from: https://www.sciencedirect.com/science/article/pii/S0749379717306992. https://doi.org/10.1016/j.amepre.2017.11.011.

Gavurová, B., Kováč, V., \& Vagašová, T. (2017). Standardised mortality rate for cerebrovascular diseases in the Slovak Republic from 1996 to 2013 in the context of income inequalities and its international comparison. Health economics review, 7(1), 7. Retrieved from https://www.ncbi.nlm.nih.gov/pmc/articles/PMC5289125/. https://doi.org/10.1186/s13561-016-0140-4.

Gavurova, B., Vagasova, T., \& Grof, M. (2017), Educational Attainment and Cardiovascular Disease Mortality in the Slovak Republic. Economics and Sociology, 10(1), 232-245. DOI: 10.14254/2071-789X.2017/10-1/17

Glymour, M. M., Clark, C. R., \& Patton, K. K. (2014). Socioeconomic determinants of cardiovascular disease: recent findings and future directions. Current Epidemilogy Reports, 1(2), 89-97. Retrieved from https://link.springer.com/article/10.1007/s40471014-0010-8. https://doi.org/10.1007/s40471-014-0010-8. 
Granados, J. A. T. (2012). Economic growth and health progress in England and Wales: 160 years of a changing relation. Social Science \& Medicine, 74(5), 688-695. Retrieved from https://www.sciencedirect.com/science/article/pii/S0277953612000159. https://doi.org/10.1016/j.socscimed.2011.11.019.

Gravelle, H., Wildmanb, J., \& Sutton, M. (2012). Income, income inequality and health: what can we learn from aggregate data?. Social Science \& Medicine, 54(4), 577-589. Retrieved from https://www.sciencedirect.com/science/article/pii/S0277953601000533. https://doi.org/10.1016/S0277-9536(01)00053-3.

Griskevicius, V., Tybur, J. M., Delton, A. W., \& Robertson, T. E. (2011). The influence of mortality and socio-economic status on risk and delayed rewards: A life history theory approach. Journal of Personality and Social Psychology, 100(6), 1015-1026. Retrieved from https://www.ncbi.nlm.nih.gov/pmc/articles/PMC3298774/. https://doi.org/10.1037/a0022403.

Jakubowska, A. (2016). Health and limitations in health as the determinant of human capital effectiveness: perspective of the EU Member States. Journal of International Studies, 9(1), pp. 240-251. DOI: 10.14254/2071-8330.2016/9-1/18

Halaskova, R. (2018). Structure of General Government Expenditure on Social Protection in the EU Member States. Montenegrin Journal of Economics, 14(4), 007-021.

Halliday, T. J. (2014). Unemployment and mortality: Evidence from the PSID. Social Science \& Medicine, 113, 15-22. Retrieved from https://www.sciencedirect.com/science/article/pii/S027795361400269X. https://doi.org/10.1016/j.socscimed.2014.04.038.

Houweling, T. A. J., \& Kunst, A. E. (2009). Socio-economic inequalities in childhood mortality in low- and middle-income countries: a review of the international evidence. British Medical Bulletin, 93 (1), 7-26. Retrieved from https://academic.oup.com/bmb/article-lookup/doi/10.1093/bmb/ldp048. https://doi.org/10.1093/bmb/ldp048.

James, J. (2015). Health and education expansion. Economics of Education Review, 49, 193 215. Retrieved

from https://www.sciencedirect.com/science/article/pii/S027277571500117X. https://doi.org/10.1016/j.econedurev.2015.10.003.

Kabayama, M., \& Kamide, K. (2018). Socio-economic Factors and CVD. Reference Module in Biomedical Sciences. Encyclopedia of Cardiovascular Research and Medicine, 442445. Elsevier. Retrieved from: https://www.researchgate.net/publication/317563752_Socioeconomic_Factors_and_CV D. https://doi.org/10.1016/B978-0-12-801238-3.99609-0.

Korda, R., J., Soga, K., Joshy G., Calabria, B., Attia, J., Wong, D., \& Banks, E. (2016). Socio-economic variation in incidence of primary and secondary major cardiovascular disease events: an Australian population-based prospective cohort study. International Journal for Equity in Health, 15(1), 189. Retrieved from: https://equityhealthj.biomedcentral.com/articles/10.1186/s12939-016-0471-0. https://doi.org/10.1186/s12939-016-0471-0.

Lešková, M., Magurová, D., \& Derňárová, L. (2011). Prevencia civilizačných ochorení so zameraním na ochorenie arteriálna hypertenzia. Molisa - Medicínsko-ošetrovatel'ské listy Šariša, $8, \quad 70-76 . \quad$ Retrieved from: https://www.unipo.sk/public/media/16593/Le\%C5\%A1kov\%C3\%A1\%20M.,\%20Magu rov\%C3\%A1\%20D.,Der\%C5\%88\%C3\%A1rov\%C3\%A1,\%C4\%BD..pdf.

Masters, R. K., Link, B. G., \& Phelan, J. C. (2014). Trends in education gradients of 'preventable' mortality: A test of fundamental cause theory. Social Science \& Medicine, 127 , 
https://www.sciencedirect.com/science/article/pii/S0277953614006698.

https://doi.org/10.1016/j.socscimed.2014.10.023.

Medeiros, J. \& Schwierz, C. (2013). Estimating the Drivers and Projecting Long-Term Public Health Expenditure in the European Union: Baumols Cost Disease. Economic Papers 507. Brussels, Belgium: European Commission. Retrieved from http://ec.europa.eu/economy_finance/publications/economic_paper/2013/pdf/ecp507_en .pdf. https://doi.org/10.2765/54565.

Organisation for Economic Co-operation and Development (2015). Fiscal Sustainability of Health Systems: Bridging Health and Finance Perspectives. Paris, France: Organisation for Economic Co-operation and Development Publishing. Retrieved from https://read.oecd-ilibrary.org/social-issues-migration-health/fiscal-sustainability-ofhealth-systems_9789264233386-en. https://doi.org/10.1787/9789264233386-en.

Organisation for Economic Co-operation and Development (2017). Health at a Glance 2017: OECD Indicators. Paris, France: Organisation for Economic Co-operation and Development Publishing. Retrieved from: https://read.oecd-ilibrary.org/social-issuesmigration-health/health-at-a-glance-2017_health_glance-2017-en.

https://doi.org/10.1787/health_glance-2017-en.

Reeves, A., Basu, S., McKee, M., Meissner, C., \& Stuckler, D. (2013). Does investment in the health sector promote or inhibit economic growth?. Globalization and Health, 9, 43. Retrieved from https://globalizationandhealth.biomedcentral.com/articles/10.1186/1744-8603-9-43. https://doi.org/10.1186/1744-8603-9-43.

Renton, A., Wall, J., \& Lintott, J. (2012). Economic growth and decline in mortality in developing countries: An analysis of the World Bank development datasets. Public Health, 126(7), 551-560. Retrieved from https://www.sciencedirect.com/science/article/pii/S0033350612001138. https://doi.org/10.1016/j.puhe.2012.03.011.

Riemenschneider, H., Balázs, P., Balogh, E., Bartels, A., Bergmann, A., Cseh, K., Faubl, N., \& Füzesi, Z. (2016). Do socio-cultural factors influence medical students' health status and health-promoting behaviors? A cross-sectional multicenter study in Germany and Hungary. BMC Public Health, 16(576). Retrieved from https://bmcpublichealth.biomedcentral.com/articles/10.1186/s12889-016-3228-1. https://doi.org/10.1186/s12889-016-3228-1.

Roth, G. A, Dwyer-Lindgren, L., Bertozzi-Villa, A., Stubbs, R. W., Morozoff, C., Naghavi, M., Mokdad, A. H., \& Murray, C. J. L. (2017). Trends and Patterns of Geographic Variation in Cardiovascular Mortality Among US Counties, 1980-2014. The Journal of the American Medical Association, 317(19), 1976-1992. Retrieved from 10.1001/jama.2017.4150. https://jamanetwork.com/journals/jama/fullarticle/2626571.

Schofield, D., Shrestha, R., Percival, R., Passey, M., Callander, E., \& Kelly, S. (2013). The personal and national costs of CVD: Impacts on income, taxes, government support payments and GDP due to lost labour force participation. International Journal of Cardiology, 166(1), 68-71. Retrieved from https://www.sciencedirect.com/science/article/pii/S0167527311017955. https://doi.org/10.1016/j.ijcard.2011.09.066.

Stankovičová, I., \& Vojtková, M. (2007). Viacrozmerné štatistické metódy s aplikáciami. Bratislava, Slovak Republic: Iura Edition.

Suhrcke, M., Nugent, R.A., Stuckler, D., \& Rocco, L. (2006). Chronic disease: an economic perspective. London, United Kingdom of Great Britain and Northern Ireland: The Oxford Health Alliance.

Retrieved

from 
https://www.who.int/management/programme/ncd/Chronic-disease-an-economicperspective.pdf.

Svihrova, V., Barakova, A., Szaboova, V., Kamensky, G., \& Hudeckova, H. (2016). Trends in standardized mortality rates for select groups of cardiovascular diseases in Slovakia between 1980 and 2010. Public Health, 130, 43-50. Retrieved from https://www.sciencedirect.com/science/article/pii/S0033350615003790. https://doi.org/10.1016/j.puhe.2015.09.006.

Thompson, L. E., \& Daugherty, S. L. (2017). Gender disparities in cardiovascular disease prevention. Heart, 103, 492-498. https://doi.org/10.1136/heartjnl-2016-310788.

van Baal, P. H., \& Wong, A. (2012). Time to death and the forecasting of macro-level health care expenditures: Some further considerations. Journal of Health Economics, 31(6), 876-887.

Retrieved from https://www.sciencedirect.com/science/article/pii/S0167629612001129. https://doi.org/10.1016/j.jhealeco.2012.08.003.

Vandersteegen, T., Marneffe, W., Cleemput, I., \& Vereeck, L. (2015). The impact of no-fault compensation on health care expenditures: An empirical study of OECD countries. Journal of Health Economics, 32(1), 88-105. Retrieved from https://www.sciencedirect.com/science/article/pii/S0168851014002401. https://doi.org/10.1016/j.healthpol.2014.09.010.

Walsemann, K. M., Goosby, B. J., \& Farr, D. (2016). Life course SES and cardiovascular risk: Heterogeneity across race/ethnicity and gender. Social Science \& Medicine, 152, 147-155. Retrieved from https://www.sciencedirect.com/science/article/pii/S0277953616300399. https://doi.org/10.1016/j.socscimed.2016.01.038.

World Health Organization. (2018). Noncommunicable diseases: Key facts. Retrieved from http://www.who.int/mediacentre/factsheets/fs355/en/.

Zahra, A., Lee, E.-W., Sun, L. Y., \& Park, J.-H. (2015). Cardiovascular disease and diabetes mortality, and their relation to socio-economical, environmental, and health behavioural factors in worldwide view. Public health, 129(4), 385-395. Retrieved from: https://www.sciencedirect.com/science/article/pii/S0033350615000323. https://doi.org/10.1016/j.puhe.2015.01.013. 